МЕТОДЫ КОНТРОЛЯ И ДИАГНОСТИКА В МАШИНОСТРОЕНИИ

DOI: 10.26730/1999-4125-2020-1-20-28

УДК 006.9

\author{
ПРОДЛЕНИЕ СРОКА СЛУЖБЫ РЕДУКТОРОВ \\ ОТЕЧЕСТВЕННЫХ ЭКСКАВАТОРОВ С ПОМОЩЬЮ МЕТОДОВ \\ НЕРАЗРУШАЮЩЕГО КОНТРОЛЯ
}

\title{
EXTENTION OF THE DOMESTIC EXCAVATORS GEARBOX SERVICE USING METHODS NON-DESTRUCTIVE TEST
}

\author{
Дрыгин Михаил Юрьевич, \\ канд. техн. наук, e-mail: mike.drygin@ gmail.com \\ Mikhail Yu. Drygin, C. Sc. In Engineering, \\ Курышкин Николай Петрович, \\ канд. техн. наук, доцент, e-mail: kemnik@mail.ru
}

Nikolai P. Kuryshkin, C. Sc. In Engineering, Associate Professor

Кузбасский государственный технический университет имени Т.Ф. Горбачева, 650000, Россия, г. Кемерово, ул. Весенняя, 28

T.F. Gorbachev Kuzbass State Technical University, 28, street Vesennyaya, Kemerovo, 650000,

Russian Federation

\section{Аннотация:}

Эффективность работы основных технологических машин угольных разрезов - экскаваторов - в значительной мере определяется надежностью работы редукторов. В этих условиях особое значение приобретает система планово-предупредительных ремонтов, включающая профилактический контроль работоспособности редукторов, плановое техническое обслуживание и ремонт с использованием методов неразрушающего контроля (НК). Проведенные в течение семи лет на разрезах Кузбасса и Красноярского края производственные эксперименты и наблюдения позволили выработать методику проведения неразрушающего контроля редукторов. Установлено, что 98,9\% дефектов редукторов выявляются визуально-измерительным контролем, а остальные 1,1\% - контролем проникающими веществами. Введение категории «условно недопустимые» дефекты позволило 47\% зубчатых колес с недопустимыми дефектами перевести в эту категорию. Наблюдения показали, что зубчатые зацепления с такими дефектами выполняли свои функиии от одного года до шести лет. Экономия ремонтного фонда на замене только одного такого зубчатого колеса составила не менее 2 млн рублей.

Ключевые слова: Экскаватор, редуктор, зубчатое зачепление, дефект, неразрушающий контроль, питтинг, недопустимый износ, визуально-измерительный контроль.

\section{Abstract:}

The efficiency of the main technological coal mining machines that is excavators is largely determined by the reliability of the gearboxes. Under these conditions, a system of scheduled preventive repairs, including preventive monitoring of the performance of gearboxes, scheduled maintenance and repairs using non-destructive testing (ND) methods is of particular importance. Production experiments and observations which have been carried out over seven years at the open pits of Kuzbass and Krasnoyarsk Region made it possible to develop a method for conducting non-destructive testing of gearboxes. It was found that $98.9 \%$ of gearbox defects are detected by visual measuring control, while the remaining $1.1 \%$ are detected by penetrating substances. The introduction of the category of "conditionally unacceptable" defects allowed $47 \%$ of gears with unacceptable defects to be transferred to this category. Observations showed that gears with such defects performed their functions from one to six years. The savings in the repair fund for the replacement of only one such gear amounted to at least 2 million 
rubles.

Key words: Excavator, gearbox, gearing, defect, non-destructive testing, pitting, excessive wear, visual measurement control.

\section{Введение}

В Российской Федерации более $70 \%$ объема добычи угля приходится на угольные разрезы. Это объясняется очевидным преимуществом открытого способа добычи по сравнению с подземным. Кузнецкий угольный бассейн является одним из крупнейших в России и мире [1-6]. Основными технологическими машинами, работающими на разрезах Кузбасса, являются отечественные шагающие экскаваторы (ЭШ) и карьерные гусеничные экскаваторы (ЭКГ) [7].

Большинство узлов экскаватора за период его жизненного цикла подвергаются ремонту. Такие основные узлы, как двигатель, редукторы, гидромоторы, насосы и гидроцилиндры редко вырабатывают ресурс более 36 тыс. моточасов, а в

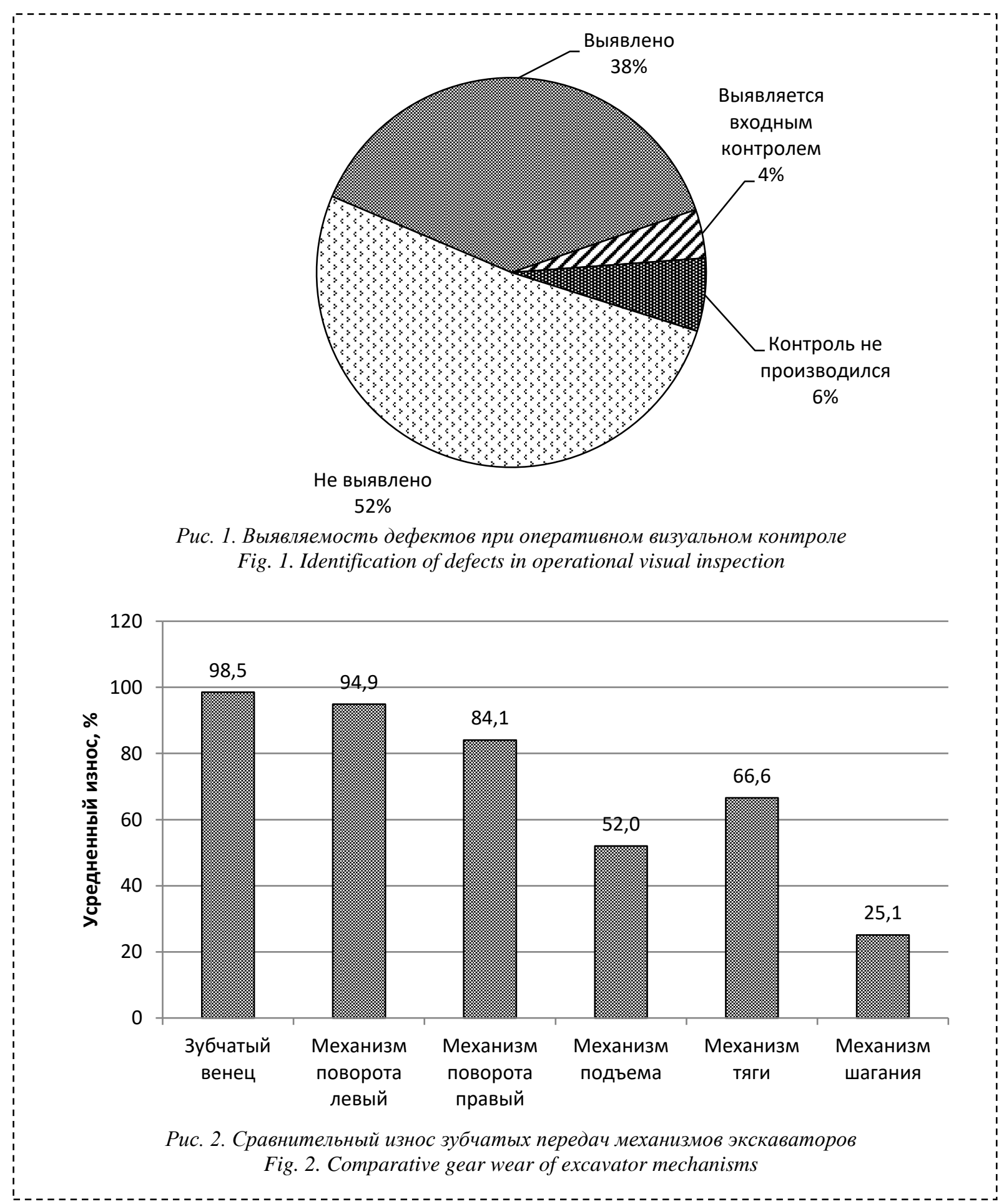


Вестник Кузбасского государственного технического университета. 2020. № 1, с.20-28

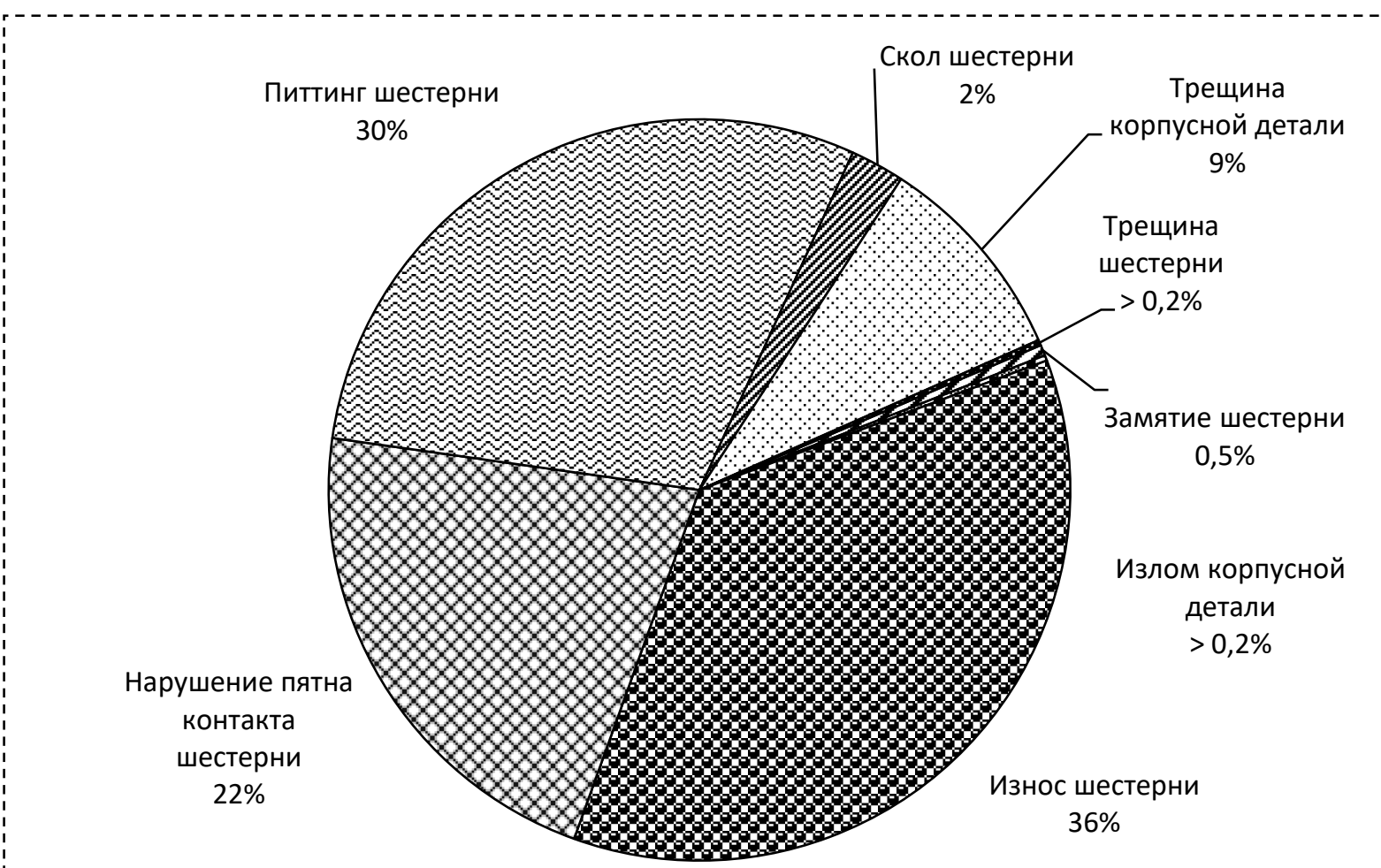

Рис. 3. Соотношение типовых дефектов деталей редукторов Fig. 3. The ratio of typical defects of gear parts

среднем их ресурс ограничен 16 .. 24 тыс. моточасами службы. В итоге через 5 лет эксплуатации подвергаются замене практически все узлы, причем не по одному разу. Это объясняется особо тяжелыми условиями работы агрегатов как по климатическим, так и по силовым факторам [8].

Особо значимыми агрегатами экскаватора являются редукторы. Согласно классической теории механизмов, зубчатые зацепления представляют собой высшие кинематические пары, площадь контакта сопряженных поверхностей в которых теоретически равна нулю. В результате передачи больших мощностей на этих поверхностях возникают большие контактные напряжения, являющиеся причиной их разрушения [9]. Подобное происходит и в подшипниковых опорах валов. Однако замена подшипниковых узлов не является дорогостоящей в решении проблемой. Выход же из строя зубчатого зацепления является существенной проблемой, так как поломка любого из редукторов ведет к полной остановке экскаватора. Значительные трудоемкость ремонта и стоимость запасных частей, часто отсутствие запасных частей не только в официальном сервисе, но даже на заводеизготовителе (изготовление только под заказ) значительно усугубляет данную проблему, а факт того, что разрушение одного из составных узлов влечет разрушение других, а иногда и всего редуктора, делает
безаварийной
значимой.

В этих условиях особое значение приобретает система планово-предупредительных ремонтов, включающая профилактический контроль работоспособности редукторов, плановое техническое обслуживание и ремонт с использованием методов неразрушающего контроля (НК) [10].

\section{Результаты и обсуждение}

За период с февраля 2012 года по октябрь 2018 года на горных предприятиях ОАО «РУСАЛ», ООО «Топкинский цемент» и десяти разрезах Кузбасса было выполнено с использованием методов неразрушающего контроля 70 комплексных обследований редукторов гусеничных экскаваторов ЭКГ - 37 единиц, шагающих ЭШ - 33 единицы. Всего было проконтролировано 564 редуктора или 18795 зубчатых передач, в них входящих.

Контроль зубчатых передач проводился по двум направлениям [11]. Первое направление включало в себя визуальный контроль в течение 20 ... 40 минут на один редуктор в процессе эксплуатации машинистами экскаваторов и ремонтным персоналом, не прошедшим специальную подготовку.

Второе направление включало контроль при плановом техническом обслуживании, требующий 


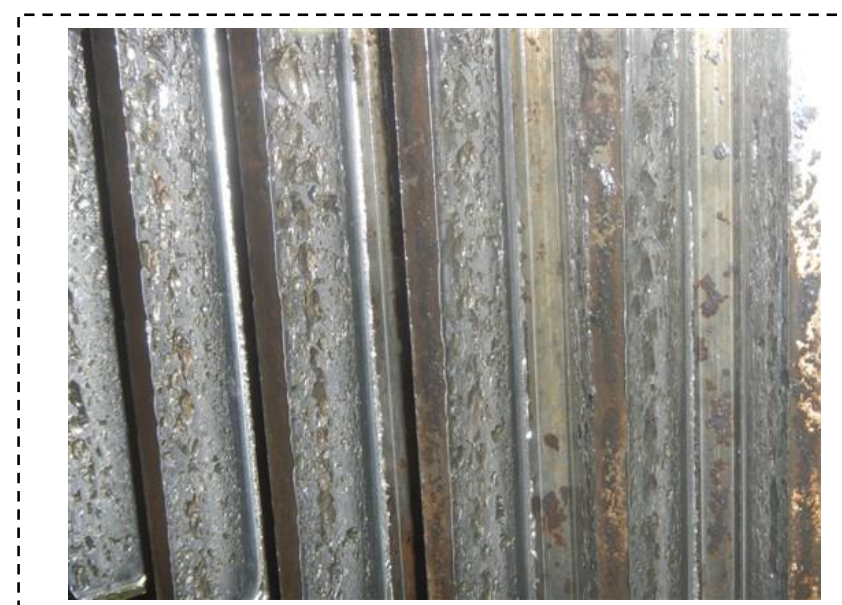

a)

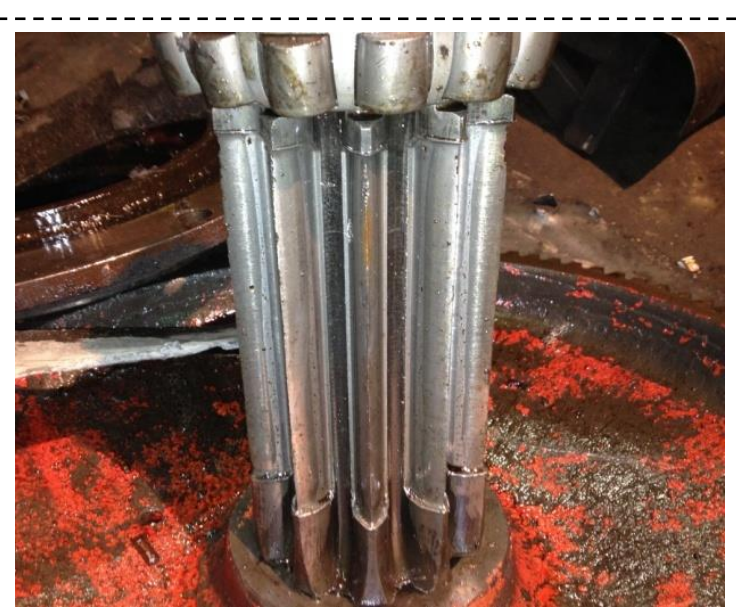

б)

Рис. 4. Недопустимые дефекты шестерен: питтинг а) и износ зубьев б) Fig. 4. Unacceptable gear defects: pitting a) and tooth wear b)

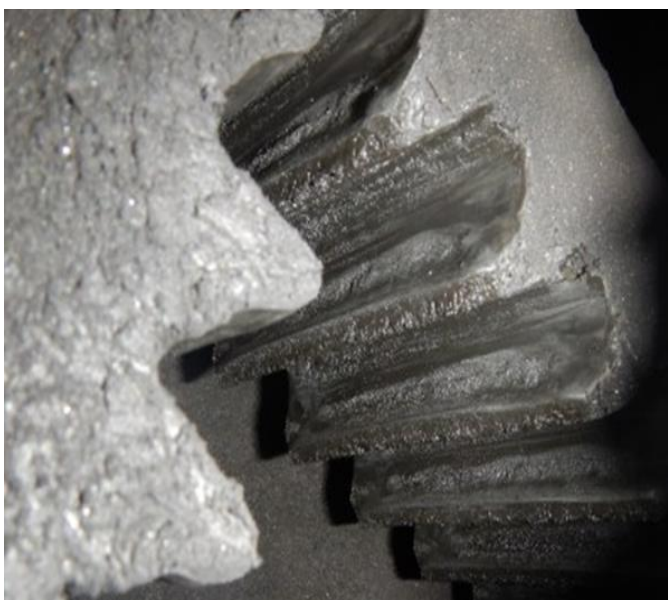

a)

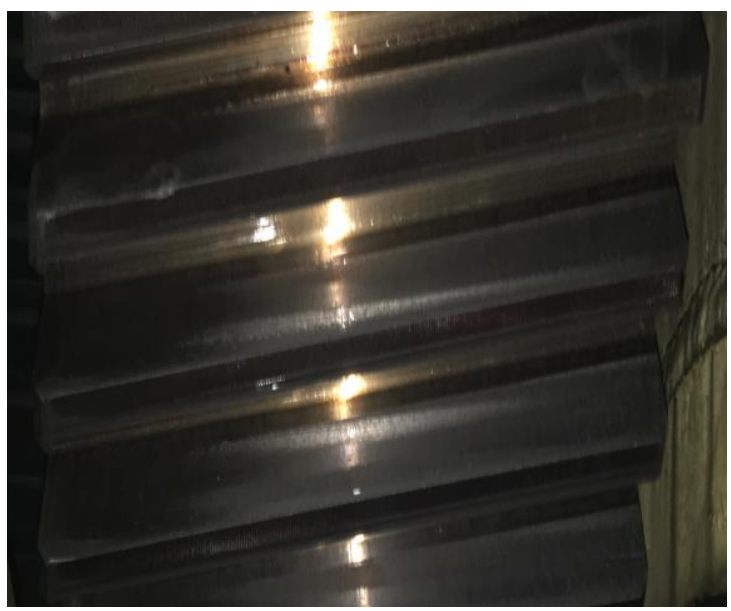

б)

Рис. 5. Нарушение пятна контакта: недопустимое а) и условно недопустимое б) Fig. 5. Violation of the contact spot: unacceptable a) and conditionally unacceptable b)

значительного времени и проводимый обученным специалистом по неразрушающему контролю, имеющим эффективную мотивацию к поиску дефектов.

В рамках исследований по первому направлению проводился визуальный контроль, дефекты фиксировались [12]. Результаты контроля явно указывают на значительную эффективность периодических осмотров даже персоналом без специальной подготовки. Как видно из диаграммы (рис. 1), в 38\% случаев были выявлены дефекты, своевременное предотвращение которых позволило предотвратить аварийную остановку экскаваторов. Между тем 6\% дефектов было пропущено, так как на этих узлах контроль не производился по производственным причинам. В $4 \%$ случаев аварийной остановки могло бы не быть, если бы был произведен входной контроль деталей. В 52\% случаев дефекты не были выявлены и стали впоследствии причиной аварийного ремонта.
Таким образом, доказана эффективность оперативного контроля технического состояния зубчатых зацеплений эксплуатирующим персоналом, не прошедшим специальную подготовку по НК. Выявленные при этом дефекты, такие как частичный или полный излом зуба и недопустимый износ зубьев, носят критический характер.

В рамках исследований по второму направлению проводился контроль методами НК с применением мерительного инструмента и приборов неразрушающего контроля. Контроль проводился во время технического обслуживания (ТО) редукторов и во время их капитального ремонта [13]. По результатам замеров износа зубчатых передач редукторов и открытых зубчатых венцов построена диаграмма, представленная на рис. 2. Замеры толщины зубьев производились в соответствии с технологическими картами заводаизготовителя в двух точках эвольвентной поверхности. 


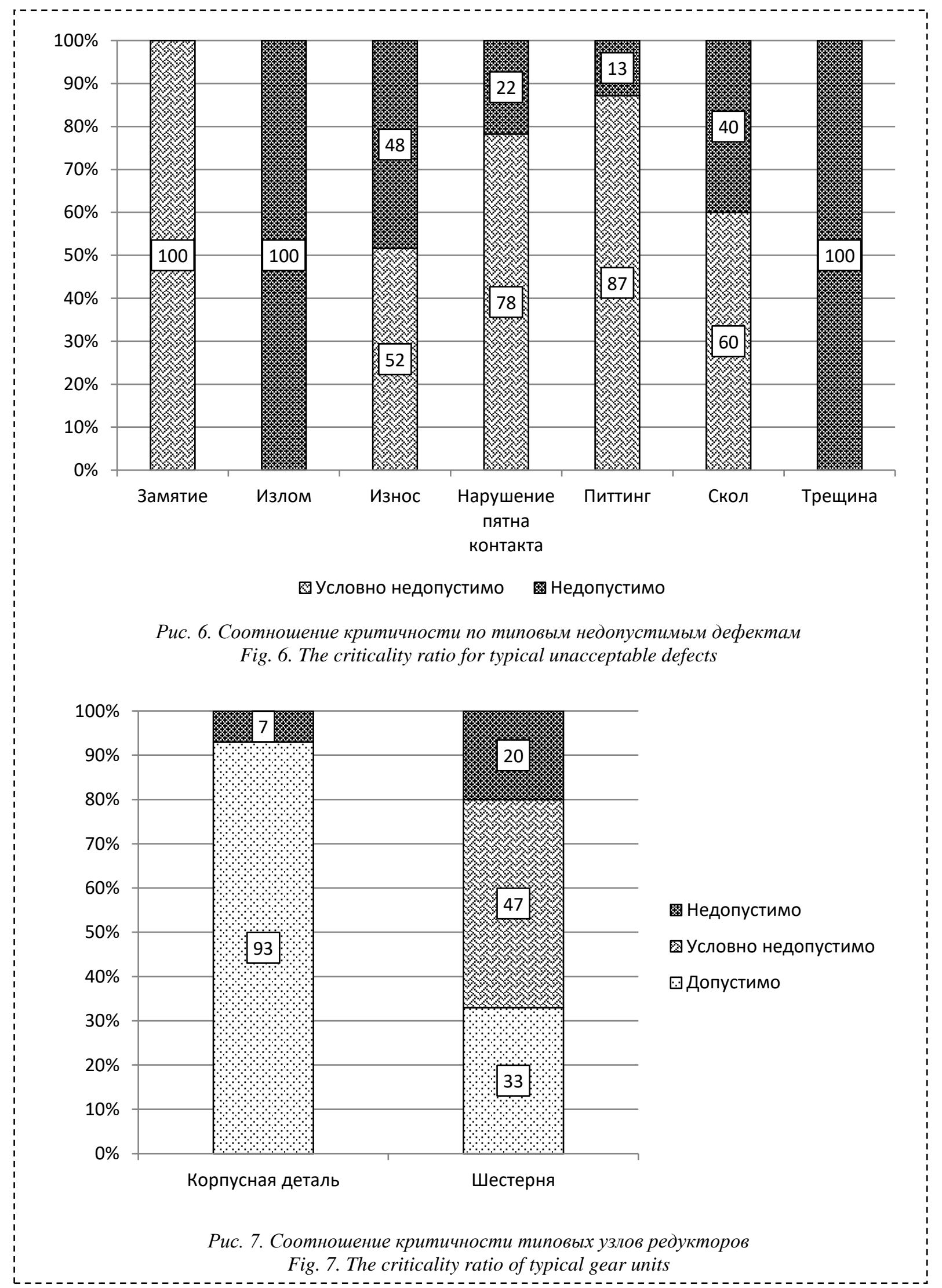

Самый высокий удельный процент износа приходится на узлы, выполняющие функцию поворота - механизм поворота и открытый зубчатый венец. Удельный процент износа зубчатого венца - 98,5\%, механизма поворота $94,9 \%$ и $84,1 \%$, правого и левого соответственно. На третьем месте механизм тяги $(66,6 \%)$, далее следует механизм подъема (52\%) и механизм 
шагания/хода (25,1\%). Данная ситуация объясняется тем, что зубчатые передачи механизмов поворота работают в более щадящих режимах, чем другие редукторы. Это позволяет им находиться в работоспособном состоянии весь срок службы экскаватора с неоднократными продлениями. Замене эти механизмы подлежат, как правило, с наработкой, превышающей 20 лет.

После проведения визуально-измерительного контроля (ВИК), согласно действующей нормативно-технической документации, был назначен следующий порядок контроля: контроль проникающими веществами (ПВК), далее магнитно-люминесцентный контроль (МК) и затем ультразвуковой контроль (УК). Такой порядок обусловлен информативностью методов [14, 15]. Установлено, что 98,9\% дефектов редукторов было выявлено ВИК, остальные $1,1 \%$ дефектов выявлялись ПВК и подтверждались МК. В целом эффективность ВИК можно оценить как высокую и не требующую применения дополнительных методов. Однако в целях обеспечения высокого уровня качества контроля целесообразно применять метод ПВК для выявления 100\% поверхностных дефектов зубчатых передач. Применение УК на корпусных деталях и зубчатых передачах оказалось малоэффективным ввиду того, что практически все дефекты носят поверхностный характер, а подповерхностные дефекты на исследованных 564 единицах редукторов отсутствовали. В тоже время стоит отметить, что метод УК незаменим при проведении входного контроля и выявления технологических дефектов в виде подповерхностных несплошностей деталей [16].

Результаты комплексного обследования редукторов методами НК представлены в виде круговой диаграммы на рис. 3.

Из диаграммы видно, что самые распространенные дефекты зубчатых передач - это критический износ (36\%), питтинг (30\%) и нарушение пятна контакта (22\%). Далее следуют трещины корпусной детали - 9\%. Незначительный процент дефектов составляют сколы зубьев шестерни (2\%), трещины шестерни (>0,2\%), замятия $(0,5 \%)$ и излом корпуса $(>0,2 \%)$. Следует отметить, что все трещины корпусной детали были обнаружены на корпусах редукторов, на выходных валах которых крепились тяговые барабаны канатов без дополнительных подшипниковых опор. А изломы корпусных деталей стали следствием развития трещин.

Анализ полученной информации по дефектам редукторов экскаваторов привлеченными экспертами с учетом опыта эксплуатации методом экспертных оценок позволил выявить пути продления срока службы зубчатых зацеплений. Это, в свою очередь, дало значительную экономию при проведении ремонтных работ. Из категории недопустимых дефектов, согласно инструкциям по капитальному ремонту и технологическим картам, была выделена подкатегория «условно недопустимые» дефекты. Исходя из опыта эксплуатации, зубчатые зацепления с такими дефектами еще имеют значительный остаточный ресурс работы и не влияют на безопасность и непрерывность эксплуатации.

За весь период проведения наблюдений (с 2012 по 2018 годы) не было выявлено ни одного простоя экскаваторов по причине недопустимого износа или питтинга зубьев шестерен. Как правило, простои, связанные с разрушением зубчатых передач, возникали из-за разрушения подшипниковых узлов редукторов либо из-за нарушений норм эксплуатации, приводящих к недопустимым нагрузкам и выкалыванию зубьев. Bсе это указывает на целесообразность переработки норм по разбраковке зубчатых передач редукторов отечественного производства.

Подобная ситуация складывается и с нарушением пятна контакта зубьев зацепления. В большинстве случаев этот вид дефекта является несущественным, хотя, несомненно, требует корректирующих действий путем регулировки зацепления. Однако, как правило, рабочая поверхность зуба уже нарушена и регулировка не изменит ситуацию, но сама зубчатая пара может находиться в эксплуатации еще длительное время, продолжительность которого зависит от условий эксплуатации. На рисунке 5 приведены примеры нарушения пятна контакта в зубчатом зацеплении. В целом дефекты с пометкой «условно недопустимые» могут находиться в эксплуатации, но требуют периодического ВИК контроля.

Анализ основных дефектов зубчатых зацеплений (рис. 3) показал, что из всех недопустимых дефектов $63 \%$ можно смело отнести в разряд «условно недопустимых». Причем обобщенная формализация критериев перевода дефектов в категорию «условно недопустимые» практически невозможна. Она должна быть привязана к конкретным зубчатым передачам конкретных редукторов.

На рис. 6 представлена диаграмма критичности типовых дефектов, отнесенных в категорию недопустимых.

Анализ соотношения критичности типовых узлов (рис. 7) показал, что 7\% корпусных деталей и $20 \%$ зубчатых колес обладают недопустимыми дефектами и требуют срочных корректирующих мероприятий. Подавляющее большинство (93\%) корпусных деталей и треть (33\%) зубчатых колес находятся в работоспособном состоянии. Почти половина зубчатых колес (47\%) имеют условно недопустимые дефекты (износ, питтинг, нарушение пятна контакта).

Наблюдения показали, что зубчатые зацепления с недопустимыми дефектами, переведенными в категорию условно недопустимых, выполняли свои функции от одного 
года до шести лет. А некоторые, например, тихоходные зубчатые колеса лебедок тяги и подъема экскаваторов ЭШ, продолжали эксплуатироваться, выйдя за рамки эксперимента. Экономия ремонтного фонда на замене только одного такого зубчатого колеса составила не менее 2 млн рублей.

\section{Выводы}

1. Доказана эффективность оперативного контроля технического состояния зубчатых зацеплений эксплуатирующим персоналом, не прошедшим специальную подготовку по НК. Не менее $38 \%$ дефектов выявляется оперативным визуальным контролем. Выявленные при этом дефекты, такие как частичный или полный излом зуба и недопустимый износ зубьев, носят критический характер.

2. Не менее 4\% зубчатых передач, приводящих к аварийным остановкам экскаваторов, связано с установкой запасных частей низкого качества. Исключить подобную ситуацию можно введением входного контроля.

3. Установлено, что $98,9 \%$ дефектов редукторов выявляются визуально-измерительным контролем, а остальные $1,1 \%$ - контролем проникающими веществами с подтверждением магнитным контролем. На этом основании с целью оптимизации процесса неразрушающего контроля зубчатых передач рекомендуется использовать в первую очередь метод ВИК с подтверждением методами ПВК или МК. Все это указывает на целесообразность переработки норм по разбраковке зубчатых передач редукторов экскаваторов отечественного производства.
4. Введение
категории
«условно

недопустимые» дефекты позволило 47\% зубчатых колес с недопустимыми дефектами перевести в эту категорию. Наблюдения показали, что зубчатые зацепления с такими дефектами выполняли свои функции от одного года до шести лет, а некоторые, например, тихоходные зубчатые колеса лебедок тяги и подъема экскаваторов ЭШ, продолжали эксплуатироваться, выйдя за рамки эксперимента. Экономия ремонтного фонда на замене только одного такого зубчатого колеса составила не менее 2 млн рублей.

\section{СПИСОК ЛИТЕРАТУРЫ}

1. Arden, H., and Tverdov, A. Resource and reserve valuation practices in countries forming the Russian Commonwealth of Independent States, in Mineral resource and ore reserve estimation. The AusIMM guide to good practice: The Australasian Institute of Mining and Metallurgy Monograph 30, 2014. - P. 825-834.

2. Kovalev V.A., Khoreshok A.A., Litvin O.I. The Role of Innovative Technologies in Solving Kuzbass Coal Industry Geo-Ecological Problems. The 8th Russian-Chinese Symposium. Coal in the 21st Century: Mining, Processing and Safety, 2016. - P. 287.

3. Плакиткин, Ю.А. Угольная промышленность России на мировом рынке угля: тенденции перспективного развития / Ю.А. Плакиткин, Л.С. Плакиткина, К.И. Дьяченко // Уголь. - 2016. - №7. - С. 12-16.

4. Российская экономика, цифры и факты. Часть 5. Угольная промышленность. [Электронный pecypc] - Режим доступа: http://utmagazine.ru/posts/10449-ekonomika-rossii-cifry-i-fakty-chast-5-ugolnayapromyshlennost [25.02.2020].

5. Статистический обзор Информационной службы по развивающимся рынкам «Угольный сектор России» (2013) [Электронный ресурс] - Режим доступа: https://www.emis.com/sites/default/files/Russia\%20Coal\%20Mining\%20Sector\%20Report.pdf - [25.02.2020].

6. Drygin, M.Y., Kurychkin N.P., Bakanov A.A. Strategy of Russian coal mining enterprises' excavator park technical state correction. E3S Web of Conferences The Second International Innovative Mining Symposium. 2017. - P. 03011.

7. Анистратов, К.Ю. Анализ рынка карьерных экскаваторов и самосвалов в РФ и странах СНГ // Горная Промышленность. - 2016. - №2. - С. 16.

8. Drygin, M.Y., Kuryshkin N.P. Increasing the quality of excavators'planetary reduction gearboxes on the basis of dimensional analysis and geometrical characteristics of tooth wheels. Journal of Physics: Conference Series. 2018. - P. 012030.

9. Артоболевский, И.И. Теория механизмов и машин. - М.: Наука, 1988. - 640 с.

10.Махно, Д.Е. Техническое обслуживание и ремонт экскаваторов на карьерах Севера / Д.Е. Махно и [др.] // Организация и механизация. - Иркутск: Изд-во Иркут. ун-та, 1993. - 200 с.

11.Глущенко, П.В. Техническая диагностика: Моделирование в диагностике и прогнозировании состояния технических объектов. - М.: Вузовская книга, 2004. - 248 с.

12.Инструкция по визуальному и измерительному контролю (РД 03-606-03). Серия 03. Вып. 39 / Колл. авт. - М.: Федеральное государственное унитарное предприятие «Научно-технический центр по безопасности в промышленности Госгортехнадзора России», 2004. - 112 с. 
13.Положение о планово-предупредительном ремонте оборудования открытых горных работ на предприятиях угольной промышленности СССР / Колл. авт. - М.: Научно-исследовательский и проектноконструкторский институт угольной промышленности, 1990. - 40 с.

14.Гончаров, И.Б. Дефектоскопия оборудования в угольной промышленности. / И. Б. Гончаров, К.М. Матангин. - М.: Изд-во Недра, 1990. - 148с.

15.Глазунов, Л.П. Проектирование технических систем диагностирования / Л. П. Глазунов, А.Н. Смирнов. - М.: Энергоатомиздат, 1982. - 168 с. $-209 \mathrm{c}$.

Ермолов, И.Н. Ультразвуковой контроль / И.Н. Ермолов, М.И. Ермолов. - М.: Изд-во «Азимут», 2006.

\section{REFERENCES}

1. Arden H. and Tverdov A. The AusIMM guide to good practice: The Australasian Institute of Mining and Metallurgy Monograph 30, 2014. P. 825-834.

2. Kovalev V.A., Khoreshok A.A., Litvin O.I. The 8th Russian-Chinese Symposium. Coal in the 21st Century: Mining, Processing and Safety, 2016. P. 287.

3. Plakitkin Ju.A., Plakitkina L.S. D'jachenko K.I. Ugol'naja promyshlennost' Rossii na mirovom rynke uglja: tendencii perspektivnogo razvitija [Coal industry of Russia in the global coal market: perspective development trends] Coal. 2016. No.7. P. 12-16.

4. Rossijskaja jekonomika, cifry i fakty. Chast' 5. Ugol'naja promyshlennost'. [Russian economy, figures and facts. Part 5. Coal industry.]. URL: http://utmagazine.ru/posts/10449-ekonomika-rossii-cifry-i-fakty-chast-5ugolnaya-promyshlennost (accessed: 25.02.2020).

5. Statisticheskij obzor Informacionnoj sluzhby po razvivajushhimsja rynkam «Ugol'nyj sektor Rossii» (2013) [Statistical review of the Emerging Markets Information Service "Coal Sector of Russia"] URL: https://www.emis.com/sites/default/files/Russia\%20Coal\%20Mining\%20Sector\%20Report.pdf （accessed: 25.02.2020)

6. Drygin M.Y., Kurychkin N.P., Bakanov A.A. E3S Web of Conferences The Second International Innovative Mining Symposium. 2017. Vol. 15, P. 03011. doi: 10.1051/e3sconf/20171503011

7. Anistratov K.Ju. Analiz rynka kar'ernyh jekskavatorov i samosvalov v RF i stranah SNG [Market analysis of mining excavators and dump trucks in the Russian Federation and the CIS countries]. Gornaja Promyshlennost' [Mining]. 2016. - №2. - P. 16.

8. Drygin M.Y., Kuryshkin N.P. Journal of Physics: Conference Series. 2018. Vol. 944, P. 012030. doi: 10.1088/1742-6596/944/1/012030

9. Artobolevskij I.I. Teorija mehanizmov i mashin [Theory of mechanisms and machines]. Moscow: Nauka, 1988. $-640 \mathrm{p}$.

10.Mahno D.E. Tehnicheskoe obsluzhivanie i remont jekskavatorov na kar'erah Severa [Maintenance and repair of excavators in the quarries of the North] / D.E. Mahno i [dr.] // Organizacija i mehanizacija [organization and mechanization]. Irkutsk: Irkutsk University Press, 1993. - 200 p.

11.Glushhenko P.V. Tehnicheskaja diagnostika: Modelirovanie v diagnostike i prognozirovanii sostojanija tehnicheskih ob\#ektov [Technical diagnostics: Modeling in the diagnosis and prediction of the state of technical objects]. - Moscow: University book, 2004. - 248 p.

12.Instrukcija po vizual'nomu i izmeritel'nomu kontrolju (RD 03-606-03). Serija 03. Vyp. 39 [Instructions for visual and measuring control (RD 03-606-03). Series 03. Vol. 39] / Koll. avt. - M.: Federal'noe gosudarstvennoe unitarnoe predprijatie «Nauchno-tehnicheskij centr po bezopasnosti v promyshlennosti Gosgortehnadzora Rossii» [Federal State Unitary Enterprise "Scientific and Technical Center for Safety in Industry of the Gosgortekhnadzor of Russia"], 2004. - 112 p.

13.Polozhenie o planovo-predupreditel'nom remonte oborudovanija otkrytyh gornyh rabot na predprijatijah ugol'noj promyshlennosti SSSR [Regulations on scheduled preventive maintenance of open cast mining equipment at the enterprises of the USSR coal industry] / Koll. avt. - M.: Nauchno-issledovatel'skij i proektno-konstruktorskij institut ugol'noj promyshlennosti [Coal Research and Design Institute], 1990. - 40 p.

14.Goncharov I.B. Defektoskopija oborudovanija v ugol'noj promyshlennosti [Flaw detection of equipment in the coal industry]. / I. B. Goncharov, K. M. Matangin. - Moscow: Publishing House "Nedra", 1990. - 148p. 
15.Glazunov L.P. Proektirovanie tehnicheskih sistem diagnostirovanija [Designing technical diagnostic systems] / L. P. Glazunov, A. N. Smirnov. - Moscow: Jenergoatomizdat, 1982. - 168 p.

16.Ermolov I.N. Ul'trazvukovoj kontrol'[Ultrasonic testing] / I.N. Ermolov, M.I. Ermolov. - Moscow: Publishing House «Azimut», 2006. - 209 p. 